\title{
RANCANG BANGUN SISTEM KONTROL DAN PEMANTAUAN AQUAPONIC BERBASIS IoT PADA KELURAHAN KUTAJAYA
}

\author{
Nina Rahayu ${ }^{1}$ \\ Wiranti Sri Utami ${ }^{2}$ \\ Muhamad Misbach Razabi ${ }^{3}$
}

\begin{abstract}
Dosen STMIK Raharja Tangerang ${ }^{1,2}$, Mahasiswa STMIK Raharja Tangerang ${ }^{3}$
Jl. Jenderal Sudirman No.40 Modernland Cikokol, Tangerang ${ }^{1,2,3}$

e-mail: nina.rahayu@ raharja.info ${ }^{1}$, wiranti.utami@ raharja.info $^{2}$, misbach@ ${ }^{\text {raharja.info }}{ }^{3}$
\end{abstract}

\begin{abstract}
ABSTRAK
Akuaponik merupakan teknik bercocok tanam dengan menggabungkan tanaman dan ikan, melalui teknik ini cocok untuk masyarakat daerah perkotaan yang di daerahnya terdapat banyak pabrik industri serta jarang adanya lahan terbuka hijau, teknik ini bisa di lakukan di pekarangan rumah yang lahannya tidak luas. Teknik akuaponi khanya mengandalkan air tanpa menggunakan tanah sebagai media tanamnya, sehingga daerah yang mempunyai sumber air melimpah lebih disarankan menggunakan teknik ini dibandingkan teknik bercocok tanam pada umumnya. Penelitian ini di lakukan dengan metode pengumpulan data, analisa, studi pustaka, prototype, dan juga pengujian. Dalam penelitian ini peneliti melakukan penelitian tentang alat rancang bangun system control dan pemantauan akuaponik berbasis IoT dengan sebuah sensor ultrasonic dan dht22 yang bisa membaca ketinggian air dan suhu serta kelembaban di sekitar akuaponik. Sensor tersebut akan member informasike mikrokontroller arduino uno, kemudian mikrokontroler akan memerintahkan pompa air, lampu, dan kipas untuk hidup ataumati, akuaponik pun dapat di pantau melalui smartphone android, sehingga memudahkan pengguna akuaponik.
\end{abstract}

Kata kunci: Akuaponik, Arduino Uno, Dht22, Ultrasonik.

\section{ABSTRACT}

Aquaponic is a cultivation technique that combines plants and fish, and this technique is suitable for urban communities where there are many industrial plants and rarely green open land, this technique can be done in the yard of the house whose land is not wide. The aquaponic technique relies only on water without the use of soil as its planting medium, so that areas with abundant water sources are more advisable to use this technique than planting techniques in general. This research is done by data collection method, analysis, literature study, prototype, and also testing. In this study the researchers conducted research on aquaponic-based control and aquaponic control system design with an ultrasonic sensor and dht22 which can read the water level and temperature and humidity around the Iaponik. The sensor will inform the arduinouno microcontroller, then the microcontroller will command the water pump, lamp, and fan to turn on or off, aquaponic can monitor from smartphone android, making it easier for the iaponic users.

Keyword: Aquaponic, Arduino Uno, Dht22, Ultrasonic. 


\section{PENDAHULUAN}

Perkembangan populasi manusia yang semakin meningkat menyebabkan semakin bertambahnya jumlah penduduk. Tidak hanya itu, infrastruktur yang ada juga mengalami perkembangan sehingga sudah sedikit lahan penghijauan di daerah perkotaan, maka kota hanya maju secara ekonomi namun mundur secara ekologi. Dengan kemunduranekologi, masyarakat sebaiknya ikut serta dalam memajukan kembaliekologi dengan cara bercocok tanam, salah satunya adalah dengan teknik

bercocok tanam aquaponic yang bisa dilakukan di halaman rumah.

Aquaponic memberikan alternatif bercocok tanam dilahan terbatas dengan menggabungkan akuakultur dan hidroponik dalam lingkungan yang simbiotik. Nutrisi akuaponik bisa didapat dengan mudah, yaitu diperoleh dari kotoran ikan. Umumnya pada akuakultur eksresi dari ikan yang dipelihara akan terakumulasi di air dan meningkatkan toksisitas jika tidak dibuang, dalam akuaponik, kotoran ikan akan dipecah menjadi nitrat dan nitrit melalui proses alami dan dimanfaatkan oleh tanaman sebagai sumber nutrisi. Dalam kegiatan ini sistem hidroponik berperan sebagai filter bagi lingkungan ikan.

Metode monitoring dan pengontrolan aquaponic otomatis ini diharapkan dapat memberikan dampak nyata kepada masyarakat yang ingin bercocok tanam dengan teknik aquaponic, sehingga tidak perlu datang melihat secara langsung aquaponic karna sistem ini dapat memantau suhu, kelembaban dan mengukur ketinggian air pada kolam melalui smartphone

Dari hasil observasi bahwa di kelurahan yang berada di Kabupaten Tangerang, tepatnya berada di Kelurahan Kutajaya, membutuhkan suatu inovasi baru dalam penghijauan dan pemanfaatan lahan yang ada agar lebih berguna dan efisien sebab sistem kebun yang ada di Kelurahan Kutajaya masih menggunakan sistem berkebun pada umumnya belum menggunakan sistem aquaponic.

\section{RUMUSAN MASALAH}

Rumusan permasalahan penelitian yang dapat ditarik adalah sebagai berikut:
1. Bagaimana merancang aquaponic dengan menggunakan mikrokontroler Arduino Uno?

2. Bagaimana sistem aquaponic dapat membaca suhu, kelembaban, dan ketinggian air?

3. Bagaimana sistem aquaponic dapat dikontrol dan di awasi secara real time dengan smartphone?

\section{TUJUAN PENELITIAN}

Terdapat beberapa tujuan dalam penyusunan laporan penelitian ini, yaitu sebagai berikut:

1. Mewujudkan sistem aquaponic yang lebih efisien dan terotomatisasi menggunakan mikrokontroler arudino.

2. Membuat sebuah rancang bangun sistem aquaponic yang dapat dikontrol langsung menggunakan smartphone.

3. Membuat sistem aquaponic yang dapat mengukur ketinggian air pada kolam, dan dapat mengukur suhu serta kelembaban disekitar area aquaponic.

\section{MANFAAT PENELITIAN}

Dari penelitian yang telah dilakukan terdapat beberapa manfaat yang dihasilkan, diantaranya:

1. Dapat memantau ketinggian air pada kolam ikan aquaponic secara otomatis. 
2. Dapat memantau suhu dan kelemababn aquaponic secara otomatis.

3. Dapat mengontrol aquaponic menggunakan smartphone.

4. Dapat mengontrol aquaponic menggunakan smartphone.

5. Sebagai contoh untuk warga sekitar agar dapat menerapkan sistem aquaponic ini.

\section{LITERATURE REVIEW}

Metode studi pustaka (literature review) dilakukan guna menunjang dari metode observasi dan wawancara yang telah dilakukan.Pengumpulan informasi sangat dibutuhkan dalam menggali referensi- referensi yang berkaitan sesuai dengan penelitian yang dilakukan. diantaranya yaitu:

1. Penelitian ini dilakukan oleh Zulheman, Haidar Afkar Ausha dan Rachma Maharani Ulfa pada tahun (2016), yang berjudul "Pengembangan Sistem Smart Akuaponik". Penelitian ini membahas tentang sebuah sistem embedded aquaponic pintar (smart aquaponic) yang sudah dikembangkan yang dapat me-monitoring kadar ph air, ketinggian air, dan pakan ikan yang terintegrasi dengan mobile application dan jaringan internet secara real-time. Sehingga, mobilitas pengguna aquaponik dapat lebih mudah dan efisien. [1]

2. Penelitian ini dilakukan oleh Saaid, Fadhil, Megat Ali, dan Noor pada tahun (2013), yang berjudul "Automated Indoor Aquaponic Cultivation Technique". Penelitian ini membahas tentang sistem untuk memepertahakan pertumbuhan dan tingkat ketahanan hidup ikan dan tanaman, dengan memantau tingkat air yang diinginkan, suhu yang dipantau dalam tangki ikan, suhu yang dipantau di area tanaman dan jumlah makanan yang diinginkan. Sedangkan arduino bergungsi sebagai otak yang digunakan untuk menerima informasi dari sensor dan memberikan respon sebagai umpan balik. [2]

3. Penelitian ini dilakukan oleh Shafeena T pada tahun (2016), yang berjudul "Smart Aquaponics System: Challenges and Opportunities". Penelitian ini membahas tentang sistem kontrol yang diperlukan aquaponik untuk pemantauan dan kontrol sistem yang dinamis dengan menggunakan mikrokontroler arduino uno agar aquaponik dapat dimaksimalkan kinerjanya. [3]

4. Penelitian ini dilakukan oleh Wahyu Adi Prayitno, Adharul Muttaqin, dan Dahnial Syauqy pada tahun (2015), yang berjudul "Sistem Monitoring Suhu, Kelembaban, dan Pengendali Penyiraman Tanaman Hidroponik menggunakan Blynk Android". Penelitian ini membahas aquaponik yang dapat di-monitoring dengan menggabungkan kemampuan arduino mega sebagai sistem akuisisi data yang dilengkapi ethernet shiel untuk pengiriman data melalui jaringan internet, sensor DHT22 untuk pewaktuan secara real time. Arduino mega juga dihubungkan dengan relay untuk mengatur penyalahan pompa penyiram atau sirkulator air. [4]

\section{PEMECAHAN MASALAH}

Setelah mengamati dan meneliti dari beberapa pemasalahan yang terjadi, terdapat beberapa alternatif pemecahan dari permasalahan yang dihadapi yaitu, dengan menggunakan Arduino Uno, aquaponic bisa dikendalikan dan dipantau menggunakan smartphone yang telah di setting terlebih dahulu.

\section{LANDASAN TEORI}

\section{a. Arduino Uno}

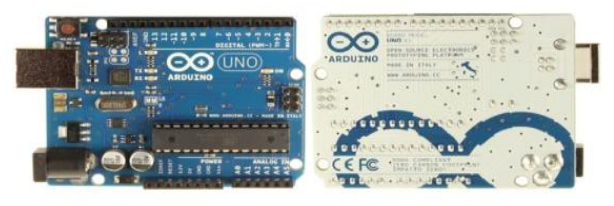

Gambar 1. Arduino Uno 
Menurut Kadir Arduino merupakan perangkat keras sekaligus perangkat lunak yang memungkinkan siapa saja melakukan pembuatan prototipe suatu rangkaian elektronika yang berbasis mikrokontroler dengan mudah dan cepat. [5]

Menurut Prasetya Arduino merupakan kit elektronik atau papan rangkaian elektronik yang didalamnya terdapat komponen utama28 yaitu sebuah chip mikrokontroler dengan jenis AVR dari perusahaan Atmel serta software pemrograman yang berlisensi open source. [6]

\section{b. Internet of Thing}

Menurut Sulistyanto ,IoT didefinisikan sebagai interkoneksi dari perangkat komputasi tertanam (embedded computing devices) yang teridentifikasi secara unik dalam keberadaan infrastruktur internet [7]. Bisa dikatakan IoT adalah teknologi jaringan yang bisa mengkoneksikan perangkat dengan internet.

\section{c. Sensor Ultrasonik}

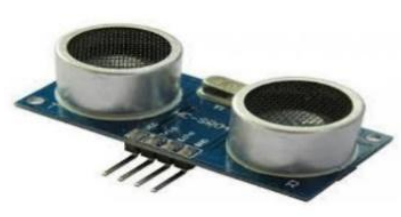

Gambar 2. Sensor Ultrasonik

Menurut Kumar Ultrasonic sensors are devices that use electrical - mechanical energy transformation to measure distance from the sensor to the target object. [8]

Menurut Santoso sensor ultrasonik adalah sebuah sensor yang berfungsi untuk mengubah besaran fisis (bunyi) menjadi besaran listrik dan sebaliknya. [9]

\section{d. Sensor DHT22}

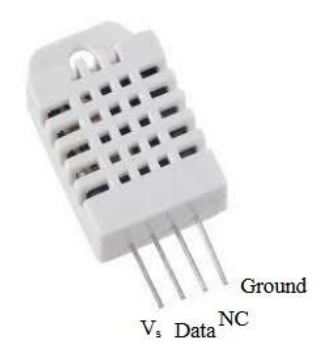

Gambar 3. DHT22

DHT22 merupakan salah satu sensor suhu dan kelembaban yang juga dikenal sebagai sensor AM2302. Sensor DHT22 ini memiliki beberapa kelebihan yaitu sebagai berikut:

1. Data hasil pengukuran sensor sudah berupa sinyal digital dengan konversi dan perhitungan dilakukan oleh MCU 8-bit.

2. Sensor terkalibrasi secara akurat dengan kompensasi suhu di ruang penyesuaian dengan nilai koefisien kalibrasi tersimpan dalam memori OTP terpadu.

3. Rentang hasil pengukuran suhu dan kelembaban sensor DHT22 lebih lebar.

\section{METODE PENELITIAN}

Metode pengembangan sistem yang digunakan yaitu metode prototype, metode ini dapat memberikan ide bagi pembuat maupun pemakai tentang cara kerja atau cara sistem yang 
dibuat berfungsi. sebagaimana yang dikemukakan oleh Raymond McLeod Jr. adalah sebagai berikut:

\section{Mengidentifikasikan kebutuhan pemakai}

Analis sistem mewawancarai pemakai untuk mendapatkan gagasan dari yang diinginkan pemakai terhadap sistem.

2. Mengembangkan Prototype

Analis sistem mungkin berkerja sama dengan spesialis informasi lain, menggunakan satu atau lebih peralalatn prototype untuk mengembangkan sebuah prototype.

\section{Menentukan Apakah Prototype dapat diterima}

Analis mendidik pemakai dalam penggunaan prototype dan memberikan kesempatan kepada pemakai untuk membiasakan diri dengan sistem, tahap pengujian.

\section{Menggunakan Prototype}

Prototype ini menjadi sistem yang dapat di operasionalkan, tahap implementasi sistem.

\section{PERANCANGAN BLOK DIAGRAM}

Agar mempermudah peneliti dalam menjelaskan perancangan perangkat keras (Hardware), maka di gambarkan alur dan cara kerja perangkat keras pada rangkaian diagram blok pada gambar di bawah:

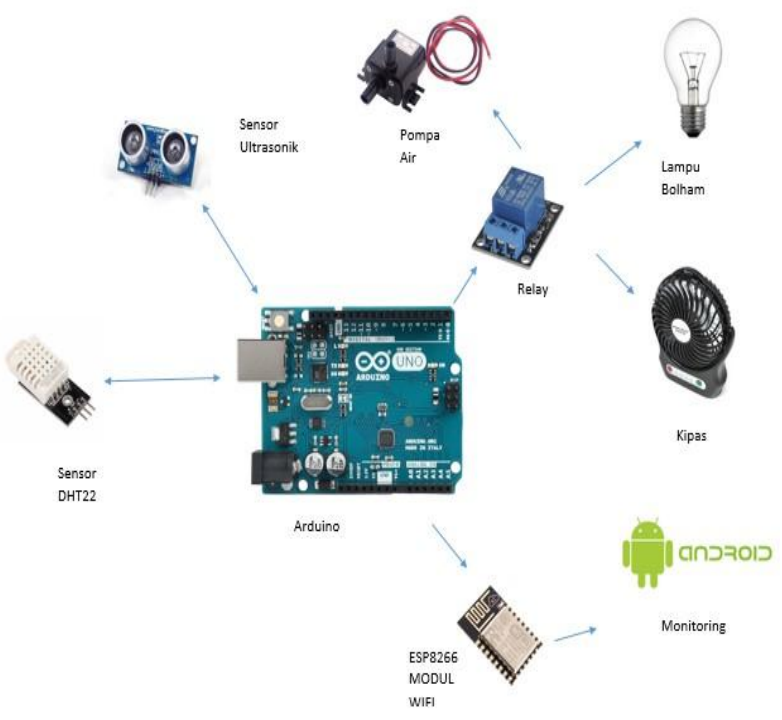

Gambar 4. Diagram Blok

Keterangan:

1. Arduino sebagai Mikrokontroler atau Otak dari keseluruhan rangkaian yang akan dibuat.

2. Sensor Ultrasonik merupakan komponen yang digunakan untuk membaca ketinggian Air.

3. Sensor DHT22 merupakan komponen yang digunakan untuk membaca kelembapan dan suhu.

4. Relay merupakan komponen yang digunakan untuk mengatur hidup dan matinya lampu bolham, kipas dan pompa air.

5. ESP8266 berfungsi sebagai modul wifi untuk menghubungkan mikrokontroler ke jaringan wifi sebagai media monitoring. 


\section{CARA KERJA ALAT}



Gambar 5. Perancangan Fisik Alat

Pada bagian ini di jelaskan cara kerja alat yaitu, penggunaan mikrokontroler Arduino uno sebagai tempat pemrosesan data yang membaca hasil input dari Sensor Ultrasonik, dan sensor DHT22 dimana data tersebut akan menentukan kerja Relay sebagai komponen Output untuk lampu bolham, kipas, danpompa air yang on dan off nya sudah diatur. Lampu bolham berfungsi sebagai pemanas ketika suhu yang dibaca.

DHT22 rendah, kipas berfungsi sebagi pendingin ketika suhu yang dibaca tinggi, dan pompa air berfungsi untuk mengaliri air kedalam kolam. Dan juga data tersebut di kirim ke database sehingga user bisa mengetahui dan melakukan pemantauan (monitoring) secara langsung melalui smartphone.

\section{FLOWCHART SISTEM}



Gambar 6. Flowchart Sistem 
Pada pembuatan sistem diperlukan sebuah gambar yang akan menjelaskan alur atau langkahlangkah dari sebuah cara kerja sistem yang dibuat. tujuan dari pembuatan flowchart adalah mempermudah pembaca untuk memahami langkah langkah serta cara kerja sebuah sistem yang dibuat. berikut flowchart sistem hasil dari penelitian yang dilakukan pada gambar diatas.

1. Pada proses awal yaitu inisialisasi sensor DHT22 dan sensor ultrasonik.

2. Padatahap selanjutnya terdapat 2 proses yaitu scanning suhu dan kelembaban dari sensor DHT22, dan scanning ketinggian air kolam dari sensor ultrasonik.

3. Pada scanning suhu dan kelembaban terbagi menjadi 2 (dua) kondisi, pertama jika suhu kurang dari $27^{\circ} \mathrm{C}$ dan kedua jika suhu lebih dari $30^{\circ} \mathrm{C}$

4. Pada konidsi suhu kurang dari $27^{\circ} \mathrm{C}$ ada 2 kondisi Ya dan Tidak, jika ya maka lampu bolham akan hidup dan jika tidak maka alat akan scanning suhu kembali.

5. Pada tahap selanjutnya jika suhu sudah normal antara $27-30^{\circ} \mathrm{C}$ ada 2 kondisi Ya dan Tidak, jika ya makan lampu bolham akan mati, jika tidak maka lampu bolham akan tetap hidup sampai suhu normal sudah tercapai.

6. Pada kondisi suhu lebih dari $30^{\circ} \mathrm{C}$ ada 2 kondisi Ya dan Tidak, jika ya maka kipas akan hidup dan jika tidak maka alat akan scanning suhu kembali.

7. Pada tahap selanjutnya jika suhu sudah normal antara $27-30^{\circ} \mathrm{C}$ ada 2 kondisi Ya dan Tidak, jika ya makan kipas akan mati, jika tidak maka kipas akan tetap hidup sampai suhu normal sudah tercapai.

8. Pada scanning ketinggian air kolam jika jarak sensor ultrasonik dengan permukaan air lebih dari $30^{\circ} \mathrm{cm}$ maka ada 2 kondisi Ya dan Tidak, jika ya maka pompa air akan hidup dan jika tidak maka alat akan scanning suhu kembali.

9. Pada tahap selanjutnya jika jarak sensor dengan permukaan air sudah normal $25^{\circ} \mathrm{cm}$ ada 2 kondisi Ya dan Tidak, jika ya makan pompa air akan mati, jika tidak maka pompa akan tetap hidup sampai mencapai ketinggian air yang sudah ditentukan.

\section{IMPLEMENTASI}

\section{a. Perangkat Keras (Hardware)}

Perangkat keras atau modul yang digunakan, memiliki fungsi dan kegunaan masing-masing, serta dapat digambarkan secara garis besar saja dan tidak secara detail dalam pembuatan suatu modu tersebut. Adapun perangkat keras yang digunakan meliputi sebagai berikut:

1. Laptop ACER E5-551 (Processor: AMD A10-7300., RAM: 8GB, Display: 15.6 Auto HD (1366x768), 1000GB HDD)

2. Arduino Uno

3. $\mathrm{PCB}$

4. ESP8266 Modul Wifi

5. LM2596 DC-DC Modul

6. konventer

7. Sensor DHT22

8. Relay Module

9. Sensor Ultrasonik

10. Pompa Air

11. Kipas Mini

12. Lampu

13. Kabel Jumper

14. Timah dan Solder 


\section{b. Perangkat Lunak (Software)}

Merupakan aplikasi maupun software yang digunakan untuk membuat program, Merancang alur diagram, dll. Adapun perangkat lunak (software) yang digunakan meliputi sebagai berikut:

1. Microsoft Word 2016

2. Web Browser (Google Chrome,Mozilla Firefox, Internet Explorer)

3. Arduino IDE ver.1.8.5

4. Fritzing

5. Paint

6. Clickc harts Diagram Flowchart Software

\section{HASIL UJI COBA}

Berikut tampilan aplikasi iot untuk pengendalian dan pemantauan pada aquaponic yang dapat di install melalui smartphone android.



Gambar 7. Tampilan Aplikasi Control dan Monitoring di android

Gambar dibawah menunjukan data yang terbaca oleh sensor suhu dan kelembaban dht22 yang ditampilkan dari LCD 16x2

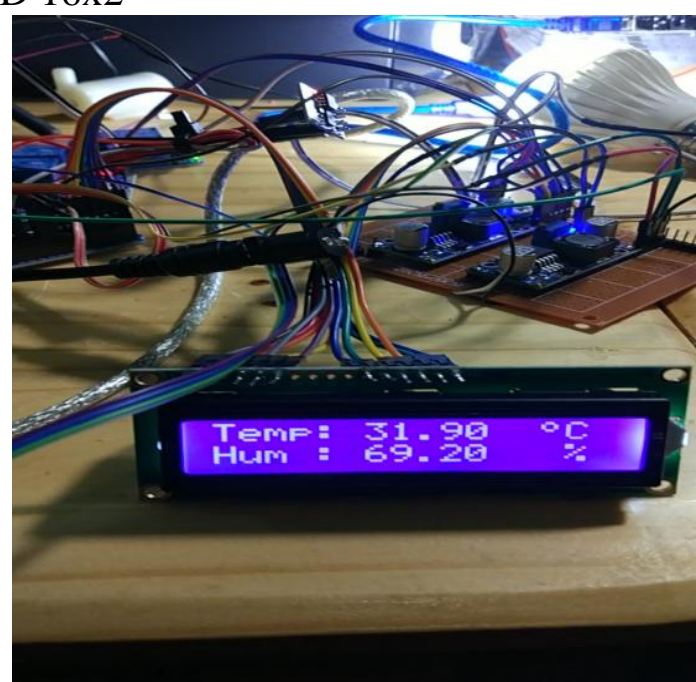

Gambar 8. Hasil Tampilan suhu dan kelembaban pada LCD 16X2 
Gambar dibawah menunjukan ketarangan kondisi suhu ,kelembaban dan ketinggian air yang ditampilkan melalui aplikasi arduino ide, jika suhu sesuai dengan yang ditentukan maka akan muncul status normal jika diluar batas yang ditentukan akan muncul status tidak normal.

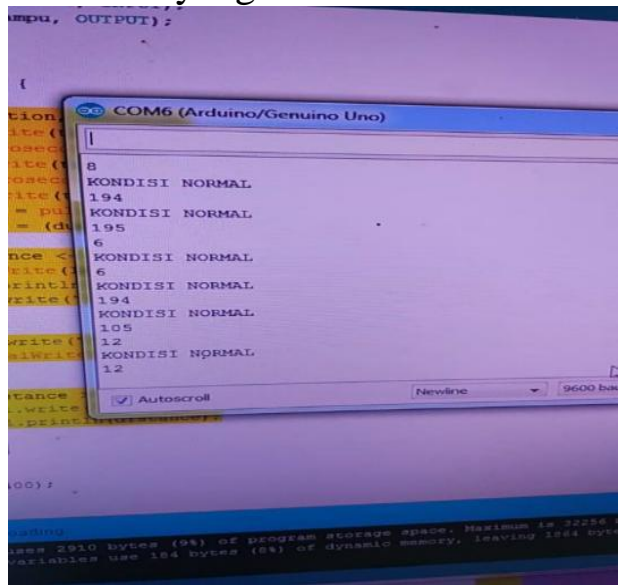

Gambar 9. Tampilan pada arduino IDE yang menyatakan suhu Normal

Gambar dibawah adalah rangkaian alat keselurahan yang terdiri dari arduino uno, esp8266, dht22, ultrasonik, relay, lampu, kipas dan lcd 16x2.



Gambar 10. Rangakian alat monitoring dan controling arduino

\section{KESIMPULAN}

Berdasarkan pembahasan yang telah diuraikan maka peneliti dapat mengambil kesimpulan bahwa:

1. Dengan menggunakan arduino uno sebagai mikrokontroler yang sudah di masukan list coding program. serta perangakat keras tambahan seperti sensor ultrasonik, dht22 dll, sehingga arduino uno akan memerintahkan komponen lain sesuai dengan program yang telah diinput kedalam mikrokontroler arduino uno.

2. Sistem aquaponic dapar membaca suhu dan kelembaban disekitarnya dengan menggunakan sensor DHT22 lalu mengguakan sensor ultrasonik untuk mengukur ketinggian air yang ada dikolam ikan aquaponic. dan sensor ESP8266 sebagai modul wifi berguna untuk mengkoneksikan alat dengan smartphone agar dapat mengirimkan hasil scan sensor ke smartphone.

3. Aquaponic yang peneliti buat memanfaatkan teknologi IoT sebagai media monitoring, yang terkoneksi dengan smartphone android yang sebelumnya sudah terinstal apk atau aplikasi untuk monitoring dan controling aquaponic. ketika pengguna membuka aplikasi maka pengguna wajib memasukan IP adress yang telah ada, lalu ketika smartphone telah 
tersambung dengan alatnya melalui jaringan wifi maka pengguna dapat memantau dan mengontrol nya melalui smartphone.

\section{SARAN}

1. Penelitian berikutnya bisa di tambahkan kamera di sekitar alat agar aquaponic lebih terpantau.

2. Penelitian berikutnya bisa di tambahkan monitoring yang lebih kompleks, seperti sensor turbidity untuk mengukur tingkat kekeruhan yang ada pada kolam ikan aquaponic.

3. Dapat di tambahkan dengan alat lain, seperti pemberian pakan otomatis untuk ikan maupun sistem lain yang akan menunjang sistem aquaponic lebih kompleks lagi.

4. Sistem yang dibuat adalah bentuk sistem yang dapat di manfaatkan maupun dirubah kedalam bentuk sistem yang lain, tidak terpakuhanya pada aquaponic saja. Bisa sebagai monitoring yang lain.

\section{DAFTAR PUSTAKA}

[1] Zulhelman, H. A. Ausha dan R. M. Ulfa, "Pengembangan Sistem Smart Aquaponik," POLITEKNOLOGI VOL. 15, pp. 181-186, 2016.

[2] Saaid, Fadhil, M. Ali dan Noor, "Automated Indoor Aquaponic Cultivation Technique," IEEE 3rd International Conference on System Engineering and Technology, pp. 285-289, 2013.

[3] Shafeena, "Smart Aquaponics System: Challenges and Opportunities," European Journal of Advances in Engineering and Technology, pp. 52-55, 2016.

[4] W. A. Prayitno, A. Muttaqin dan D. Syauqy, "Sistem Monitoring Suhu, Kelembaban, dan Pengendali Penyiraman Tanaman Hidroponik menggunakan Blynk Android," Jurnal Pengembangan Teknologi Informasi dan Ilmu Komputer, pp. 292-297, 2017.

[5] A. Kadir, Simulasi Arduino, Jakarta: PT Elex Media Komputindo, 2016.

[6] E. B. Prasetya, "Pemantau Kebocoran Ac Menggunakan Sensor Y183 Dan Lm35dz Berbasis Mikrokontroler Arduino Melalui Webserver," Jurnal Elektum, vol. Vol. 14 No. 2, pp. 49-56, 2017.

[7] M. P. T. Sulistyanto, D. A. Nugraha, N. Sari, N. Karima dan W. Asrori, "Implementasi IoT (Internet of Things) dalam pembelajaran di Universitas Kanjuruhan Malang," SMARTICS Journal, Vol. \%1 dari \%2Vol. 1, No. 1, pp. 20-23, 2015.

[8] S. Kumar dan R. P., "Ultrasonic Sensor with Accelerometer Based Smart Wheel Chair Using Microcontroller," International Research Journal of Engineering and Technology (IRJET), vol. Volume: 02 Issue: 09, pp. 537-541, 2015.

[9] H. Santoso, Panduan Praktis Arduino Untuk Pemula, Elangsakti.com, 2015. 